\title{
AÇÕES DE APRENDIZAGEM E LIDERANÇA EM CONSÓRCIOS DA ÁREA DE SAÚDE
}

\section{LEARNING AND LEADERSHIP ACTIONS IN HEALTH AREA CONSORTIUM}

\section{David Ferreira Bomfin}

Doutor em Educação com ênfase em Aprendizagem Organizacional pela WIU - Wisconsin International University. Professor do Mestrado Profissional em Administração da FEAD david.bomfin@gmail.com

Iris Barbosa Goulart Doutora e Psicologia pela PUC-SP. Professora do Mestrado Profissional em Administração da FEAD. irisgoulart@terra.com.br

Osvaldo Ribeiro de Melo Mestre em Administração pela FEAD. Secretário Executivo do CISASF josvaldomelo@gmail.com

Submissão: $14 / 03 / 2011$

Aprovação: 01/06/2012

\section{Resumo}

Nesta pesquisa sobre Aprendizagem Organizacional (AO) e formação de lideranças no âmbito do Colegiado dos Secretários Executivos de Consórcios Intermunicipais de Saúde de Minas Gerais (COSECS-MG), analisa-se de que modo se dá a AO na organização e como esta contribui para a formação de lideranças. Questionários estruturados e documentos da organização permitiram verificar como a AO se estrutura em termos de aprendizagem de manutenção ou de inovação, concepções propostas por Bennis e Nanus (1988). Após análise documental constatou-se o que a organização promove ações de aprendizagem entre seus associados com vistas à $\mathrm{AO}$; a aprendizagem de inovação foi enfatizada, mediante atuação dos líderes; e há indicadores de processos de aprendizagem de manutenção. A postura dos líderes, em relação à aprendizagem de inovação, pode permitir que, em longo prazo, a AO seja fator relevante para as organizações associadas ao COSECS-MG, aprimorando a aprendizagem existente em sua estrutura interna e nas relações externas.

Palavras-Chave: Aprendizagem Organizacional. Aprendizagem de Inovação. Aprendizagem de Manutenção. Liderança. Formação de Líderes.

\begin{abstract}
This article reports on organizational learning (OL) and leadership development of the Intermunicipality Health Consortium Executive Secretaries of the State of Minas Gerais (COSECS-MG). The main aim of the article was to verify how is OL in the organization and contributes to the leadership development. Structured questionnaires and organizational documents aimed to verify how the OL has been structured in terms of learning of maintenance or innovation learning, concepts that were proposed by Bennis and Nanus (1988). The data analysis indicated: The organization promotes learning actions to allow OL;
\end{abstract}


innovation learning was emphasized when there is action of the leaders; there are maintenance learning indicators. The posture of the leaders regarding to the innovation learning may allow in the long term that the organizational learning becomes a relevant factor for the organizations associated with COSECS-MG and that they may be able to improve the learning that exists in their internal structure and within their external relations.

Key Words: Organizational Learning. Innovation Learning. Maintenance Learning. Leadership. Leader Training. 


\section{INTRODUÇÃO}

A temática aprendizagem organizacional tem despertado a atenção de especialistas, empresários e pessoas comuns desde a segunda metade do século XX. Conforme EasterbySmith e Araújo (2001), a abordagem do tema tem contado com as contribuições da área de administração e de outras áreas, como a economia (STIGLITZ, 1987) e a sociologia (COOPEY, 1995).

A aprendizagem organizacional envolve as pessoas e suas relações, o compartilhamento de informações, a formação de lideranças, a disseminação do conhecimento e outros elementos inerentes ao processo de interação existente nas organizações e tem se apresentado como um processo-chave no atual momento do desenvolvimento, atraindo atenção crescente dos pesquisadores.

Diante da relevância que o tema da aprendizagem está conquistando no âmbito dos estudos em organizações e das diferentes perspectivas e abordagens adotadas, Bastos e Loiola (2003) mapearam o estado da arte desse campo no Brasil, tomando como base artigos publicados entre 1997 e 2001. Também Antonello (2002) apresentou uma análise da produção científica sobre três temas bastante correlacionados - aprendizagem organizacional, competências gerenciais e gestão do conhecimento, com foco nas questões epistemológicas.

Tem-se buscado compreender o significado, os princípios, as implicações, metodologias e procedimentos da $\mathrm{AO}$, focalizando dois pontos: o processo - como as organizações aprendem; e os resultados - como as organizações deveriam aprender (BITENCOURT ; AZEVEDO, 2007). Esses dois focos estão relacionados intrinsecamente com o modelo de liderança que contribui para o fomento da $\mathrm{AO}$ e da aceitabilidade da empresa para implementar e incorporar o processo enquanto estratégia empresarial necessária ao aperfeiçoamento organizacional e à competitividade exigida pelo mercado.

Um dos autores deste trabalho atuou como consultor na gestão dos Consórcios Intermunicipais de Saúde (CIS) vinculados ao Colegiado dos Secretários Executivos dos Consórcios Intermunicipais de Saúde do Estado de Minas Gerais (COSECS-MG), no anobase de 2005, período de atividade gerencial da Organização Social (OS) e dos associados integrantes do sistema CIS.

A consultoria foi buscada, inicialmente, para racionalizar o planejamento e a coordenação de recursos financeiros, a otimização dos equipamentos, do pessoal, das compras conjuntas de medicamentos e outras potencializações das atividades de saúde das cidades 

consorciadas. Gradualmente, concluiu-se que seria mais adequado buscar o desenvolvimento das lideranças, de modo a fomentar o estabelecimento de um modelo de aprendizagem organizacional.

A estrutura administrativa de organizações complexas, como são os consórcios de saúde, exige do gestor um perfil empreendedor e habilidade de liderança que possa facilitar a articulação do órgão com as demandas políticas municipais e diminuir as dificuldades existentes. A partir dessa demanda é que se configurou a pesquisa que é apresentada neste artigo.

Em que pesem proposições teóricas e metodológicas sobre AO, como notadamente as de Senge (1990, 1998), Kim (1998), DiBella e Nevis (1999), dentre outros, escolheu-se, para o estudo de caso, a abordagem de aprendizagem organizacional de Bennis e Nanus (1988) como matriz teórica, uma vez que os autores apresentam os conceitos de aprendizagem de manutenção e aprendizagem de inovação a serem adotadas pelos líderes na condução de suas organizações.

Neste estudo, os conceitos de aprendizagem de manutenção e inovação são relevantes para analisar de que forma a aprendizagem organizacional, construída mediante interação do COSECS-MG com os gestores do Sistema CIS, contribui para a formação da liderança requerida para a gestão do referido sistema.

Embora esta pesquisa seja referente à área da saúde, o foco do trabalho foi centrado nos gestores e nos documentos disponíveis na organização e não em procedimentos relacionados às ações de promoção da saúde. 


\section{SOBRE A FUNDAMENTAÇÃO TEÓRICA DESTE TRABALHO}

Dois temas sustentam teoricamente esta pesquisa: aprendizagem organizacional e liderança e sobre eles são feitas algumas considerações a seguir.

O conceito de Aprendizagem Organizacional está presente na literatura sobre teoria econômica há vários anos, mas ganhou notoriedade realmente a partir da década de 1990, provavelmente devido ao valor que este conceito tem para os processos de mudança organizacional no contexto competitivo da atualidade (SOUZA, 2004).

Para Vasconcelos e Mascarenhas (2007) trata-se de um processo contínuo, caracterizado pela interação entre os indivíduos e entre os grupos de trabalhos (que aprendem com as experiências cotidianas), inseridos em sistemas sociais e tecnológicos integrados e capazes de viabilizar o desenvolvimento e a mudança organizacional.

Bennis e Nanus (1988), autores cuja abordagem é privilegiada neste trabalho, consideram que aprendizagem organizacional é: "Um processo pelo qual uma organização obtém e emprega conhecimentos novos, novas ferramentas, comportamentos e valores. Isso acontece em todos os seus níveis - entre indivíduos e grupos, bem como no sistema todo" (BENNIS; NANUS, 1988, p. 160).

Um aspecto importante da aprendizagem organizacional e que será destacado nesta pesquisa é seu caráter ao mesmo tempo individual e coletivo. Embora a aprendizagem individual não seja sinônimo de aprendizagem organizacional, pode-se concluir que não haverá aprendizagem organizacional sem a aprendizagem individual. Simon (1969) define aprendizagem organizacional como o crescimento de insights e reestruturações bem-sucedidas de problemas organizacionais por indivíduos que têm impacto nos elementos estruturais e nos resultados da organização.

Diferentemente do que ocorre na aprendizagem individual, as organizações desenvolvem e mantêm sistemas de aprendizagem que influenciam seus membros imediatos e são transmitidos aos outros membros por meio de histórias e normas organizacionais. Desse modo, seria um erro concluir que a aprendizagem organizacional é o resultado cumulativo da aprendizagem dos membros, pois as organizações têm seus sistemas cognitivos e suas memórias e desenvolvem sua visão do mundo e suas ideologias, mapas mentais, normas e valores que se preservam para além da presença de membros individuais (ARGYRIS; SCHÖN, 1978; HEDBERG, 1981). 
Deve-se realçar, ainda, que não são os conhecimentos privados de cada indivíduo que estão em jogo na aprendizagem organizacional, mas sim aqueles conhecimentos que são, de algum modo, compartilhados e que mobilizam a ação. Por outro lado, como afirma Argyris (1992), são indivíduos, agindo como agentes da organização, que produzem ações aptas à aprendizagem ou, ao contrário, que podem inibir ou produzir barreiras à aprendizagem.

Nesse sentido, o papel dos indivíduos nas organizações vem constituindo um aspecto importante para se implantar a aprendizagem organizacional, e o desafio que esse processo representa para os líderes vem merecendo considerações dos teóricos.

Nesse contexto se insere a teoria de Bennis e Nanus (1988) sobre aprendizagem organizacional e liderança. Para esses autores, o sucesso de uma organização reporta-se ao modo como o líder procede para administrar seu próprio eu e, a partir dele, fomenta a aprendizagem organizacional entre os diversos níveis organizacionais.

A postura da liderança deve ser direcionada para que a organização (re)aprenda e (re)organize sua estrutura interna a partir de sua própria experiência interna e das experiências adquiridas de outras organizações. É necessário que os diversos níveis organizacionais congreguem e partilhem habilidades para promoverem a aprendizagem organizacional.

Bomfin (2003, 2006, 2009) observa que a AO comporta quatro componentes significativos para o processo de aprendizagem: o indivíduo, o grupo, a organização e o ambiente externo, os quais podem contribuir, de forma integrada, para o processo de aprendizagem organizacional. Esse conjunto de componentes pode contribuir para o sucesso empresarial de uma organização, porém, para alcançá-lo, alguns procedimentos não podem passar despercebidos: eficiência, estratégia, abertura, flexibilidade, inovação, modernização, uso de tecnologia, transparência, entre outros. Esses atributos são fundamentais para a organização se situar no mercado.

A aprendizagem organizacional congregada pode fortalecer a estrutura organizacional, devido às mudanças estruturais e conjunturais da sociedade, as quais exigem das organizações a flexibilidade, a inovação, a agressividade e a competitividade. Tais exigências impulsionam as organizações a estarem em processo de mudança (BENNIS; NANUS, 1988).

Portanto, a organização pode implementar o processo de aprendizagem organizacional no ambiente interno, consoante as seguintes finalidades, conforme sinalizado por Bennis e Nanus (1988):

a) incorporar-se como atividades diárias das pessoas;

b) impulsionar a interação entre os indivíduos nos ambientes interno/externo; 
c) visar à busca de metas comuns;

d) buscar retroinformação em seu ambiente para prever mudanças futuras;

e) traduzir o novo conhecimento em novas metas, procedimentos, expectativas.

Nos estudos de Bennis e Nanus (1988) existem dois modelos de gestão da aprendizagem: o modelo de aprendizagem de manutenção (modelo de gestão tradicional) e o modelo de aprendizagem inovadora (modelo de gestão inovadora).

A aprendizagem de manutenção tem como foco "a aquisição de perspectivas, métodos e regras fixos para lidar com as situações conhecidas e recorrentes". Visa ao presente a partir das ações passadas por onde se tratam "as fraquezas e falhas identificadas, reforçando o sistema de aprendizagem existente". Esse tipo de aprendizagem apresenta as seguintes características: mantêm regras fixas; centra-se na solução de problemas; preserva o sistema, a estrutura existente; institucionaliza regras, sistemas; é recorrente quanto às falhas; apresenta uma estrutura de trabalho rígida: manter o status quo do sistema (BENNIS; NANUS, 1988, p. 162). Esse modelo de aprendizagem se apresenta nas organizações que valorizam a permanência dos fundamentos que as mantêm e que são preservados como patrimônio: valores, crenças e sistemas organizacionais consolidados ao longo da história organizacional.

Ainda segundo Bennis e Nanus (1988, p. 163), aprendizagem de manutenção pode comprometer a sobrevivência da organização "em épocas de turbulências, mudanças ou descontinuidades", impedindo-a de enfrentar as adversidades impostas pelo mercado, devido à rigidez.

O modelo de aprendizagem inovadora, por sua vez, apresenta-se nas organizações que buscam implementar inovação constante, metas de fomento da aprendizagem organizacional, flexibilização na estrutura organizacional, mudanças, com o propósito de aprimorar a competitividade organizacional para que a empresa possa galgar o sucesso e ratificar sua permanência no cenário empresarial a médio e longo prazos. A aprendizagem de inovação é constituída de um conjunto de ferramentas que possibilitam a reestruturação da base organizacional, potencializando as ações que promovam a mudança, a fim de tornar a organização flexível, inovadora e competitiva (BENNIS; NANUS, 1988).

Conforme Bennis e Nanus (1988), a aprendizagem inovadora apresenta as seguintes características: dar ênfase à mudança, à reestruturação, à reformulação de problema; preparar a organização para novas situações; fazer previsão: planejamento estratégico; construir contextos novos; focar em assuntos emergentes, únicos; administrar para o risco. 
Partindo dos pressupostos de que as pessoas aprendem de maneiras diferentes e que as organizações igualmente o fazem porque são constituídas por indivíduos com saberes, valores e crenças distintos, pode-se afirmar que a aprendizagem inovadora ocorre mediante reflexão constante da própria prática de aprendizagem realizada pelos diversos níveis hierárquicos da organização, como também pela própria organização que depende dela quanto ao "propósito, cultura, ambiente, estilo operativo e capacidade da organização para absorver a mudança" (BENNIS; NANUS, 1988, p. 163).

Esse ato provoca as mudanças necessárias para a ocorrência da aprendizagem inovadora, que pode contribuir para o sucesso da empresa. Entretanto, cabe ao líder viabilizar a aprendizagem inovadora no contexto organizacional, mediante "a administração do eu coletivo".

Bennis e Nanus (1988) apresentam as principais características ou pontos fortes que a organização deve ter para potencializar a aprendizagem inovadora: reinterpretação da história; experimentação; organizações análogas; processos analíticos; treinamento e educação; “desaprendizagem".

As características pontuadas sinalizam como as organizações devem se portar no cenário empresarial e como a aprendizagem inovadora pode contribuir para a efetiva prática gerencial. Nesse aspecto, Bennis e Nanus (1988, p. 170) comentam: "Com a aprendizagem efetiva, o julgamento melhora no decorrer do tempo, os pressupostos convencionais são continuamente contestados, e os níveis mais profundos do papel do ambiente e da organização são constantemente atingidos".

Para Bennis e Nanus (1988), a função do líder é relevante, porque ele pode redesenhar a organização para que esta se torne mais receptiva à aprendizagem e este novo desenho impresso à organização a transforme em organização aberta. Uma organização aberta é aquela que consegue manter, implantar e atualizar suas relações e interações com o ambiente externo, além de ter interações constantes e intensas com esse ambiente e responder rápida e flexivelmente à nova informação.

Esse tipo de organização tem como características a participação em conjunto e a rapidez para mudar e buscar novos desafios. Dessa forma, a participação e a antecipação mediadas pela liderança - contribuem para que ocorra a aprendizagem organizacional nas organizações da aprendizagem. As duas características poderão atuar "em conjunto para estender os horizontes de tempo daqueles que tomam decisões, ampliar suas expectativas, 

permitir a partilha de pressupostos e valores, e facilitar o desenvolvimento e emprego de novas abordagens" (BENNIS; NANUS, 1988, p. 179).

O outro tema que fundamenta a abordagem teórica deste trabalho se refere ao Papel da Liderança e sua relação com a Aprendizagem Organizacional.

Jackson (2000), ao analisar o ponto de vista de Senge sobre a aprendizagem organizacional, realça o novo papel dos líderes nas organizações, afirmando que eles devem desempenhar os papéis de designer, professor e facilitador, o que passa a exigir desses personagens novas competências. Aos executivos de topo são recomendadas três tarefas básicas: construir uma base de propósitos e valores fundamentais para a organização; desenvolver políticas, estratégias e estruturas capazes de expressar as ideias orientadoras em direções para o negócio; e criar processos de aprendizagem efetivos através dos quais políticas, estratégias e estruturas possam ser continuamente aprimoradas (SOUZA, 2004).

A aprendizagem organizacional recebe forte influência do tipo de liderança responsável por seu gerenciamento e da maneira como a liderança articula as relações de aprendizagem no ambiente organizacional.

Moura e Bitencourt (2006) analisaram, a partir de um levantamento histórico, de que modo a orientação estratégica de uma organização foi consolidada, considerando-se as competências organizacionais e gerenciais sob a perspectiva construtivista, inspirada na abordagem da aprendizagem organizacional. Considerando que as competências organizacionais se desdobram em competências coletivas e individuais, as autoras mencionaram a importância de se definirem os conhecimentos, habilidades e atitudes esperadas dos gestores enquanto competências gerenciais.

Para Bennis e Nanus (1988, p. 172), o líder é um "aprendiz por excelência". Ser inovador, competente, pragmático, aberto a conselhos, entusiástico, encorajador, inquisitivo, são características que a liderança deve possuir "para fomentar a aprendizagem organizacional". Essas características constituem e determinam o tipo de liderança ideal, porém divergem da liderança realmente existente.

Geralmente, o líder ideal é concebido a priori, e são atribuídos a ele predicados idealizados e perfeitos. Entretanto o líder real é aquele que recebe atributos a posteriori. Ele é imperfeito, mas busca alcançar a perfeição na aprendizagem constante que sua atuação promove no meio organizacional, entre seus superiores, pares e subordinados.

Bennis e Nanus (1988) identificaram seis atributos ou qualidades pessoais essenciais a qualquer liderança que deseja ser realmente um líder: persistência, autoconhecimento, 

disposição para assumir riscos e aceitar perdas, comprometimento, coerência e desafio, aprendizagem.

É indispensável que o líder esteja em constante processo de aprendizagem e de aperfeiçoamento; saiba fazer leituras das experiências vivenciadas e buscar modelos que agreguem valor à sua aprendizagem. Esse é o "combustível essencial para o líder, a fonte de energia que mantém a atividade por meio do aparecimento de novo entendimento, novas ideias e novos desafios". A capacidade de "aprender em um ambiente organizacional" pode determinar o maior sucesso da liderança, porque congrega uma série de habilidades necessárias à formação constante do líder: a) reconhecer e partilhar a incerteza; b) aceitar o erro; c) responder ao futuro; d) tornar-se interpessoalmente competente (escutar, nutrir, enfrentar os conflitos de valor); 5) obter autoconhecimento (BENNIS; NANUS, 1988, p. 158).

Além das habilidades apresentadas, somam-se duas características relevantes: ser líder consoante o "modelo de papel" (para que os outros o imitem); ter a capacidade de aprender com os outros e com o ambiente - a capacidade de ser ensinado.

Segundo Bennis e Nanus (1988, p. 158): “Se o líder é visto como um aprendiz no que tange ao ambiente, outros tentarão igualar-se ao modelo, e imprimir sua própria aprendizagem".

No contexto organizacional, o líder adquire a verdadeira aprendizagem, pois essa se encontra acima das aprendizagens originárias de aprendizagem de modelos ou aprendizagem a partir de experiências.

De acordo com Bennis e Nanus (1988), para fomentar a aprendizagem organizacional, o líder deve apresentar algumas características:

a) assumir riscos (fundamental para a aprendizagem): ser modelo para os outros, ou seja, ser "inovador, competente, voltado para o futuro, pragmático, aberto a conselhos [...], entusiástico e engajado";

b) ser visto como aprendiz para orientar o processo de "autodescobrimento criativo";

c) aprender com os outros e com o ambiente, ou comportar a "capacidade de ser ensinado";

d) energizar o comportamento organizacional através de recompensas e punições.

Bennis e Nanus apontam ainda formas e/ou alternativas que o líder pode utilizar para estimular a aprendizagem na organização, adequando-as ao perfil da organização:

a) reforçar o pensamento de longo prazo, a inovação e a criatividade; 
b) legitimar e respeitar a especulação e a previsão de acontecimentos futuros;

c) aceitar a mudança e a experimentação, bem como a concorrência de ideias e a criação de novas opções;

d) partilhar missões da organização;

e) encorajar novos valores e disposições organizacionais para facilitar a difusão de conhecimento e a identificação de propósitos.

Outros aspectos relacionam-se à natureza jurídica, à vocação, à finalidade, ao estilo operacional, às permanências e às mudanças que determinam as diferenças das organizações. 


\section{METODOLOGIA}

Visando a atingir o objetivo proposto, foi desenvolvida uma pesquisa cuja abordagem é qualitativa, uma vez que se pretendeu analisar aspectos que evidenciassem a contribuição da aprendizagem organizacional para a formação da liderança requerida para a gestão do sistema, sem recorrer a mensurações e sim tentando traduzir os significados apresentados. Nesse tipo de abordagem, "valoriza-se o contato direto e prolongado do pesquisador com o ambiente e a situação que está sendo estudada" (GODOY, 1995). Quanto aos meios, a pesquisa se caracteriza como descritiva, porque visa a descrever as particularidades da interação do COSECS-MG com os gestores do Sistema CIS e os resultados por ela obtidos. De acordo com Richardson (1999), os estudos descritivos permitem abranger com exatidão as características de um indivíduo, uma situação ou um grupo, bem como desvendar a relação entre os eventos. Já quanto aos meios, a pesquisa constitui um estudo de caso.

A unidade de análise foi o COSECS-MG e os sujeitos de pesquisa foram 15 (quinze) Secretários Executivos, gestores dos CIS, e 1 (um) membro da diretoria executiva do COSECS-MG. Os instrumentos de coleta de dados foram dois questionários: um fechado, que foi aplicado aos gestores dos CIS, e outro aberto, aplicado à diretoria do COSECS-MG.

Adotou-se, também, investigação documental, centrada nos seguintes documentos: Livro de Atas, Pareceres e Estatuto do COSECS-MG (2005a, 200b). Os documentos analisados podem ser assim caracterizados: o Estatuto apresenta o foro, a sede, os fins do COSECS-MG, entre outros aspectos. O Livro de Atas compreende os registros das reuniões ordinárias e extraordinárias realizadas ao longo de 2005. Os Pareceres referem-se às consultas administrativas e jurídicas respondidas pela assessoria jurídica da organização.

Os questionários foram analisados segundo perspectiva dominantemente qualitativa, a fim de dar oportunidade de se identificarem pontos de vista dos entrevistados.

Já os dados coletados nos documentos fornecidos pela organização estudada foram submetidos à análise de conteúdo documental, como se apresenta a seguir. 


\section{ANÁLISE E INTERPRETAÇÃO DOS RESULTADOS}

A análise dos documentos permitiu as seguintes inferências:

a) Em relação ao Estatuto, observou-se no Art. $2^{\circ}$ que a organização tem por finalidade, entre outras:

- congregar os Secretários Executivos dos Consórcios Intermunicipais de Saúde de Minas Gerais, funcionando como órgão permanente de intercâmbio de experiência e informações de seus membros;

- levantar e transmitir aos Consórcios Intermunicipais de Saúde o máximo de informações que possibilitem a obtenção de recursos financeiros e técnicos, buscando a ampliação de repasse dos mesmos (COSECS-MG, 2005a).

b) Em relação ao Livro de Atas, a análise centrou-se no levantamento de informações relativas às ações de aprendizagem. Verificou-se que houve quatro reuniões ao longo do ano: três reuniões extraordinárias, em 27 de janeiro, 6 de abril e 18 de agosto, e uma reunião ordinária da Assembleia Geral, em 2 de junho.

- Na reunião de 27 de janeiro, destacou-se o tema “Orientações jurídicas de aprovação do novo estatuto de acordo com o novo Código Civil”, que serviu como orientação sobre mudanças no Estatuto, em razão das alterações ocorridas na legislação, no aspecto específico referente à empresa privada e pública. Esse procedimento se enquadra em "Treinamento e Educação", segundo Bennis e Nanus (1988, p. 168), porque: “auxilia a organização a aprender a respeito de mudanças no ambiente".

- Na reunião de 6 de abril, destacaram-se as orientações referentes ao Edital sobre seleção de projetos no âmbito dos CIS em Minas Gerais.

- Na reunião ordinária da Assembleia Geral, de 2 de junho, foram destacados os temas "Programa de Informação do COSECS-MG, a Lei Consórcios" além de informações sobre o processo de avaliação dos projetos CIS. Nesse caso, as organizações, principalmente do segmento público, realizam "discussões sobre a legislação proposta, a fim de obterem retroinformação” (BENNIS e NANUS, 1988, p. 164).

- Na reunião de 18 de agosto, destacou-se a instrução sobre Processo Licitatório. Houve troca de experiência entre CIS, e registrou-se a socialização do software 
desenvolvido por um CIS associado e disponibilizado para todos os associados via COSECS.

De acordo com Bennis e Nanus (1988, p. 165) "uma organização pode testar hipóteses sobre a direção da mudança em seu ambiente, fazendo experimentos controlados e estudando seus efeitos". Nesse aspecto, o software desenvolvido por um dos CIS, constitui "um experimento com toda uma nova abordagem organizacional, para apressar os produtos, desde sua concepção até a implementação", que para os autores constitui uma "experimentação", uma das características fundamentais às organizações inovadoras (BENNIS; NANUS, 1988, p. 165).

c) Em relação à análise de Pareceres, fez-se o levantamento de dados relacionados à assessoria jurídica e técnica sobre consultas feitas em 2005. As consultas foram realizadas de forma individual, mas foram disponibilizadas para todos os associados, após emissão e envio de Parecer da assessoria jurídico-administrativa ao consulente. Em 2005, foram emitidos seis pareceres, após cada solicitação (COSECS-MG, 2005b), conforme se apresenta a seguir:

- Parecer 1 , em $1^{\circ}$ de março, consulta realizada pelo CIS Ponte Nova, referente a “necessidade de celebração de convênio com o município para repasse de valores ao consórcio";

- Parecer 2, em $1^{\circ}$ de agosto, consulta realizada pelo CIS-AEL, referente a "contratação de pessoal";

- Parecer 3, em 4 de outubro, consulta realizada pelo CIS-MOGOL, acerca de "situações inerentes ao consulente";

- Parecer 4, em 27 de outubro, consulta realizada pelo CIS-AP, referente a "solicitação de Parecer acerca da possibilidade e da licitude da compra de medicamentos para municípios consorciados através do CIS";

- Parecer 5, em 14 de dezembro, consulta realizada pelo CIS-AMAPI, referente a “análise de minuta de Protocolo de Intenções Lei no 11.107/05 sobre adequação do CIS à Lei”;

- Parecer 6, em 26 de dezembro, consulta realizada pelo CIS-VI, referente a "contratação de pessoal na vigência da Lei no 11.107/05".

A partir das descrições realizadas, verifica-se que todos os pareceres apresentam caráter instrutivo e informativo, conforme evidenciado em fragmentos de termos coletados dos pareceres: Parecer 1 - "Ser desnecessária a celebração de convênio"; Parecer 2 “contratação deverá ser precedida de concurso público"; Parecer 3 - "Procuramos [...], 

transmitir [...] orientações"; Parecer 4 - "Perfeitamente lícita [...], observadas as recomendações"; Parecer 5 - "Os consórcios existentes estão legalmente constituídos"; Parecer 6 - "mas que sejam observadas regras objetivas".

Os termos em destaque se relacionam às alíneas " $\mathrm{b}$ " e " $\mathrm{m}$ ", do Art. $2^{\circ}$ do Estatuto, o que permite inferir que os itens mencionados se caracterizam como formas de aprendizagem.

Concluindo essa análise documental, infere-se que, em relação aos dados analisados do Estatuto, Livro de Atas e dos Pareceres, a organização COSECS-MG promove ações de aprendizagem, conforme sinalizado na alínea "b" do Art. $2^{\circ}$ do Estatuto, nos seis Pareceres emitidos e nas Atas. Nessas se destacam características de "Treinamento e Educação" na reunião de 6/04 e "Experimentação", nas reuniões de 02/06 e 18/08.

A análise dos questionários aplicados aos gestores dos CIS e ao membro do COSECSMG teve como finalidade identificar deliberações e ações interpretadas como forma de aprendizagem organizacional, segundo a base teórica de Bennis e Nanus (1988).

Analisando-se os dados coletados mediante questionário fechado aplicado aos 15 gestores dos CIS, observou-se que, entre eles, as ações de aprendizagem se direcionam para a aprendizagem de inovação, ou seja: dar ênfase à mudança, à reestruturação, à reformulação de problema; preparar a organização para novas situações; fazer previsão: realizar planejamento estratégico; construir de contextos novos; colocar foco em assuntos emergentes, únicos; orientar a administração para o risco. Todavia há indicadores significativos de processos de aprendizagem de manutenção. No entanto as ações que sinalizam para a aprendizagem de inovação parecem ser resultantes da atuação do líder-gestor em sua organização, pois esses indicam comportar as seguintes características de um líder-gestor: assumir riscos; ser visto como aprendiz para orientar o processo de "autodescobrimento criativo"; aprender com os outros e com o ambiente, ou comportar a "capacidade de ser ensinado"; e energizar o comportamento organizacional com recompensas e punições. No longo prazo, esses procedimentos podem permitir que a aprendizagem organizacional seja fator relevante para as organizações associadas ao COSECS-MG, e que estas possam aprimorar a aprendizagem existente em sua estrutura interna e nas relações externas.

O questionário aberto, que foi aplicado a 1 (um) diretor da organização, teve o propósito de verificar se ocorreu processo de aprendizagem organizacional, e se este contribui para a formação de lideranças. Tendo em vista o caráter qualitativo das respostas, atribuiu-se um sistema de classificação de respostas composto por categorias relacionadas a: 

categorias se relacionam com aspectos relevantes identificados em cada resposta.

Através da classificação das categorias pesquisadas na pergunta, informa-se que todas as perguntas foram respondidas.

Sobre envio de Editais:

a) deliberações administrativas e estatutárias;

b) promoção de treinamento formal por meio de Palestras, ou envio de informações em e-mails, correio, telefone; todos conforme prerrogativas do Estatuto;

c) O Estatuto é o norte da Diretoria no aspecto finalidade (Dados - Questionário COSECS-MG).

As ações identificadas são características de organizações que promovem a aprendizagem em seu ambiente interno. Segundo Bennis e Nanus (1988), a organização deve reaprender sua própria aprendizagem para aumentar seu potencial de sobrevivência. Já Vasconcelos e Mascarenhas (2007) observam que a aprendizagem organizacional na empresa deve ser sincrônica com a aprendizagem dos empregados. Essa observação reforça o item "c" pontuado acima, pois permite ao empregado conhecer e desenvolver sua própria aprendizagem.

Portanto, o processo de aprendizagem organizacional deve ter como meta, entre outras formas, incorporar a aprendizagem no cotidiano das pessoas e permitir a interação entre elas, para que definam metas comuns e tracem mudanças para o futuro. Todos esses aspectos podem permitir a descoberta de novos conhecimentos e traduzi-los "em novas metas, procedimentos, expectativas" (BENNIS; NANUS, 1988).

Verifica-se, pois, que a organização COSECS-MG sinaliza para aspectos que impulsionam a $\mathrm{AO}$ entre CIS associados. O procedimento parece contribuir para a formação das lideranças associadas. Chegou-se a essa constatação a partir das evidências encontradas durante o processo de análise de dados realizados em relação à investigação documental e às respostas obtidas no questionário aplicado ao diretor do COSECS-MG. Esse diretor apresenta uma resposta que sinaliza como a organização promove a aprendizagem, quando afirma que o COSECS-MG procede através da realização de:

Encontros entre os seus membros, visando trocas de experiências e articulação dos mesmos; organizando e convocando reuniões, seminários e congressos com temas pertinentes ao momento; e promovendo o repasse de informações de demandas individuais de seus associados (Resposta do Sujeito 1). 
Com base na afirmação anterior e nos aspectos relevantes pontuados para cada questão em que a organização apresenta ações que se caracterizam como forma de aprendizagem, principalmente com relação às Categorias: Aprendizagem e Gestão da Aprendizagem, pode-se inferir que o COSECS-MG se caracteriza como uma organização que promove a aprendizagem.

Os resultados apresentados permitiram qualificar as lideranças do Sistema CIS, mediante temas tratados em reuniões. Para ratificar os assuntos tratados, o COSECS-MG envia "por correio e $e$-mail" as informações discutidas nas reuniões para todos os associados, inclusive para os que ficaram ausentes delas. Não foi constatado critério ou periodicidade para envio de informações, como também nenhuma política institucional para definir critérios de seleção de informações ou mesmo de aprendizagem, conforme respostas assinaladas no questionário.

A partir dos resultados descritos, pode-se inferir que o COSECS-MG sinaliza que promove a aprendizagem organizacional na interação com seus associados, como sugere o modelo de Bennis e Nanus (1988).

Embora seja finalidade estatutária, conforme reza o Artigo 20, alínea "b" e "m", principalmente, a constatação adveio dos seguintes pontos:

a) conteúdo das Atas, por meio das quais foi possível identificar aspectos referentes à aprendizagem, assim como o envio das informações discutidas;

b) os seis Pareceres analisados apresentaram caráter instrutivo e informativo;

c) na análise do questionário aplicado ao COSECS-MG, destacam-se: a forma de envio de informações (de editais, deliberações e informações gerais) e da prática de "treinamento" dispensados aos associados, por meio da promoção de Encontros, Seminários, Palestras, Reuniões, seguida de envio da minuta desses eventos.

Pode-se inferir, também, que O COSECS-MG sinaliza que promove a formação de lideranças. Mediante os dados evidenciados no item anterior, pode-se afirmar que o COSECSMG contribuiu para a formação do gestor, ao promover encontros, palestras, realizar reuniões ordinárias e extraordinárias, enviar informações por e-mail, correio, telefone, emitir pareceres, tendo contribuído cada um, a seu modo, para a formação das lideranças associadas.

A aprendizagem se estrutura para o foco de aprendizagem de inovação, mas há evidência, também, que apontam para aspectos de aprendizagem de manutenção, o que é perfeitamente normal e essencial à organização (BENNIS; NANUS, 1988). 
PUC Minas E\&G - REVISTA ECONOMIA E GESTÃO

Diante do exposto, o COSECS-MG sinaliza para a aprendizagem organizacional entre os associados do Sistema CIS, e, ao fazê-lo, parece que contribui para a formação das lideranças, no aspecto de aprendizagem de inovação, uma vez que o líder, ao promover o processo de aprendizagem, também é afetado por ele. 


\section{CONCLUSÃO E CONSIDERAÇÕES FINAIS}

O presente estudo teve como objetivo principal identificar e analisar como se dá o processo de aprendizagem organizacional na interação entre COSECS-MG e gestores do Sistema CIS para a formação de lideranças. Com base nos estudos realizados sobre aprendizagem organizacional e nas informações obtidas na pesquisa realizada, foi verificado que há fortes indicadores que apontam para a existência de aprendizagem na relação COSECS e líderes gestores dos CIS. A aprendizagem constatada parece contribuir, de forma significativa, para a formação dos gestores. Essa aprendizagem sinaliza para o aspecto de inovação como forma de aprendizagem dos líderes nas organizações consórcios. Entretanto há indicadores significativos do aspecto de aprendizagem de manutenção, principalmente no que se refere ao modelo de gestão do CIS e atuação do líder-gestor. Vale ressaltar que o aspecto de manutenção é importante, mas essencial mesmo é o de inovação (BENNIS; NANUS, 1988).

Diante do exposto, pode-se afirmar que os objetivos da pesquisa foram alcançados, porque foi constatada a existência de aprendizagem na relação CIS-COSECS. A aprendizagem verificada parece sinalizar para a formação dos gestores e dá-se pelo aspecto inovador. Esses resultados demonstram a importância da investigação, que contribuiu para a formação do pesquisador e líder-gestor, ratifica a relevância da organização COSECS-MG, além de trazer contribuição para a literatura científica sobre aprendizagem organizacional, para os administradores e para a sociedade.

Para fortalecer ações de aprendizagem existentes no COSECS-MG e promover o processo de aprendizagem organizacional, visando à formação contínua das lideranças, conforme sinalizado nos objetivos específicos, propõem-se três sugestões: a) formatação e institucionalização de um projeto de aprendizagem; b) criação de Portal Eletrônico na World Wide Web - com acesso livre e restrito; c) criação de Conselho Político.

Para dar continuidade a esse estudo, sugere-se: a) verificar se a influência política dos gestores dos municípios consorciados pode ser caracterizada como fator de limitação ou de potencialização da atuação do líder-gestor dos CIS; b) verificar se a falta de recursos financeiros é limitador das ações dos CIS; c) identificar e analisar as condições e a formação técnica adequadas aos líderes-gestores para a promoção da aprendizagem organizacional nos Consórcios. 


\section{REFERÊNCIAS}

ANTONELLO, C. S. Estudo dos métodos e posicionamento epistemológico na pesquisa de aprendizagem organizacional, competências e gestão do conhecimento. In: ENCONTRO ANUAL DA ANPAD, 26, 2002, Salvador. Anais... Salvador: ANPAD, 2002. CD ROM

ARGYRIS, C; SCHÖN, D. Organizational learning: a theory of action perspective. Massachusetts: Addison-Wesley, 1978.

ARGYRIS, C. On organizational learning. Cambridge, MA: Blackwell, 1992.

BASTOS, A. V; LOIOLA, E. A Produção acadêmica sobre aprendizagem organizacional no Brasil. São Paulo, RAC-Revista de Administração Contemporânea, v. 7, n. 3, p. 181-201, 2003.

BENNIS, W; NANUS, B. Líderes: estratégias para assumir a verdadeira liderança. São Paulo: Harbra, 1988.

BITENCOURT, C; AZEVEDO, D. O futuro da aprendizagem organizacional: possibilidades e desafios. RAE-Revista de Administração de Empresas, v. 46, Ed. Especial, p. 110-112, 2007.

BOMFIN, D. F. Aprendizagem Organizacional no Contexto das Instituições Educacionais.ENCONTRO REGIONAL ACADÊMICO A ESTÁCIO EM FOCO MG-ESSP-RJ, 1, 2003, Juiz de Fora. Anais... Juiz de Fora: Estácio de Sá 2003. p. 35-62.

BOMFIN, D. F. Aprendizagem organizacional: contribuições para o gestor no contex to das instituições educacionais. Revista Gestão \& Tecnologia, Faculdades Pedro Leopoldo, v. 7, n. 2, p. 35-67, 2006.

BOMFIN, D. F. Desenvolvimento de líderes em prol da gestão educacional democrática: contribuições da aprendizagem organizacional. In: GOULART, I. B; PAPA FILHO, S. (Org.) Gestão de Instituições de Ensino Superior. Curitiba, Juruá, 2009. V. 1, p. 53-73.

COLEGIADO DOS SECRETÁRIOS EXECUTIVOS DE CONSÓRCIOS INTERMUNICIPAIS DE SAÚDE DE MINAS GERAIS - COSECS-MG. Estatuto do Colegiado dos Secretários Executivos dos Consórcios Intermunicipais de Saúde do Estado de Minas Gerais. Belo Horizonte: COSECS-MG, 2005a.

COLEGIADO DOS SECRETÁRIOS EXECUTIVOS DE CONSÓRCIOS INTERMUNICIPAIS DE SAÚDE DE MINAS GERAIS - COSECS-MG. Pareceres 1-6 emitidos no ano de 2005. Belo Horizonte: COSECS-MG, 2005 b.

COOPEY, J. The learning organization: power politics and ideology. Management Learning, v. 29, n. 3, p. 193-214, 1995.

DIBELLA, A; NEVIS, E. C. Como as organizações aprendem: uma estratégia integrada voltada para a construção da capacidade de aprendizagem. São Paulo: Educador, 1999. 
EASTERBY-SMITH, M; ARAÚJO, L. Aprendizagem organizacional: oportunidades e debates atuais. In: EASTERBY-SMITH, M; BURGOYNE, J; ARAÚJO, L. (Coord.) Aprendizagem organizacional e organização de aprendizagem: desenvolvimento na teoria e na prática. São Paulo: Atlas, 2001. p. 15-38.

GODOY, A. S. Introdução à pesquisa qualitativa e suas possibilidades. RAE-Revista de Administração de Empresas, v. 35, n. 2, p. 57-63, 1995.

HEDBERG, B. How organizations learn and unlearn. In: NYSTROM, P. C; STARBUCK, W. H. (Ed) Handbook of organizational design. Londres: Oxford University Press, 1981. p. 327.

JACKSON, B. G. A fantasy theme analysis of Peter Senge's learning organization. Arlington, USA, The Journal of Applied Behavioral Science, v. 36, n. 2, p. 193-209, 2000.

KIM, D. H. O elo entre a aprendizagem individual e a aprendizagem organizacional. In: KLEIN, D. A. A gestão estratégica do capital intelectual: recursos para a economia baseada em conhecimento, Rio de Janeiro: Qualitymark, 1998.

MOURA, M. C; BITENCOURT, C. C. A articulação entre estratégia e o desenvolvimento de competências gerenciais. RAE-eletrônica, v. 5, n. 1, Art. 3, jan./jun. 2006. Disponível em: <http://www.scielo.br/pdf/raeel/v5n1/29560.pdf.>. Acesso em: 15 set. 2010.

RICHARDSON, R. J. Pesquisa social: métodos e técnicas. São Paulo: Atlas, 1999.

SENGE, P. M. A quinta disciplina: arte e prática da organização que aprende. São Paulo: Editora Best Seller, 1990.

SENGE, P. M. A quinta disciplina: arte e prática da organização que aprende. São Paulo: Editora Best Seller, 1998.

SIMON, H. Sciences of the artificial. Cambridge, MA: MIT Press, 1969.

SOUZA, Y. S. Organizações de aprendizagem ou aprendizagem organizacional. São Paulo, RAE-eletrônica, v. 3, n. 1, Art. 5, 2004. Disponível em: <http://www.scielo.br/pdf/raeel/v3n1/v3n1a08.pdf.>. Acesso em: 15 set. 2010.

STIGLITZ, J. E. Learning to learn, localized learning and technological progress. In: DASGUPTA, P; STONEMAN, P. (Ed.) Economic policy and technological performance. Cambridge: Cambridge University Press, 1987.

VASCONCELOS, I. F. G; MASCARENHAS, A. O. Organizações em aprendizagem. São Paulo: Thomson Learning, 2007. 